\title{
Blowout Limits of Flames in High-Speed Airflows: Critical Damkohler Number
}

\author{
Chadwick C. Rasmussen ${ }^{1}$ and James F. Driscoll ${ }^{2}$ \\ Department of Aerospace Engineering, University of Michigan
}

\begin{abstract}
This work extends some previous research that was reported by the authors [1-4] in that empirical correlation curves are presented that summarize the lean blowout limits of cavitystabilized flames that are adjacent to supersonic, heated air flows. The correlations were obtained for two geometries: fuel injected into the cavity through the cavity aft wall and fuel injected through the cavity floor. It is found that the best correlation of the data is achieved by using the following simple representation of the Damkohler number:
\end{abstract}

$$
D a=\frac{H / U_{O o}}{\left(\frac{a_{0}}{S_{L 0}^{2}}\right)\left(\frac{1 a t m}{p}\right)^{n}\left(\frac{300 K}{T}\right)^{m}}
$$

For best correlation of the data, $n$ and $m$ were found to be 1.0. $H$ is the cavity height, $U_{00}$ is the free stream velocity ant $T$ is the free stream static temperature. The lean blowout limits for the case of aft wall fuel injection was found to be correlated by the relation: $\phi_{0}=$ $0.0043 \mathrm{Da}^{-0.26}$, where $\phi_{0}$ is the overall equivalence ratio that is based on the properly defined characteristic air mass flow rate. For the floor fuel injection cases, the lean blowout limit was correlated by: $\phi_{0}=0.0028 \mathrm{Da}^{-0.80}$. The correlations are valid over a range of conditions, including Mach numbers from 2-3, four fuel types (hydrogen, ethylene, methane, acetylene having different laminar flame speeds $S_{L_{0}}$ ), and static pressures (p) from 0.5 to $1.0 \mathrm{~atm}$. Results showed that the location of the fuel injection into the cavity is important. To explain the importance of the location of fuel injection, some images are presented that were obtained by recording the chemiluminescence. The results can be explained by three simple ideas: the injected fuel jet creates a locally fuel-rich region, the entrained air creates an effective air-jet (that starts at the upper rear corner of the cavity where the shear layer impacts on the aft wall), and the products in the recirculation zone supply heat that elevates the flame speed. The flame is observed to be nearly "attached" to the injector port if there is sufficient air near the fuel injector. For other conditions it can be "slightly lifted" and the fuel does not burn at the injector but burns a few millimeters downstream of the injector. For large fuel flow rates, the flame is highly lifted such that the cavity is flooded with fuel, and the fuel elements are convected around the cavity by the recirculation zone without burning. Then the fuel enters the shear layer at the top of the cavity and burns entirely within the shear layer. Previous theories have ignored the location of the fuel injector and have assumed that fuel-air mixing takes place immediately, creating a 'well-stirred reactor"; the present results indicate that this concept is not realistic.

\section{Introduction: Concepts of Flame Blowout in High-Speed Flows}

The goal of this work is to determine scaling laws that correlate the blowout limits for flames that are stabilized in a wall cavity that is adjacent to a high speed, heated air stream. Another goal is to explain the measured blowout scaling law by visualizing the flame location using direct chemiluminescence imaging as well as $\mathrm{CH}$, $\mathrm{OH}$

\footnotetext{
${ }^{1}$ Research Assistant, Dept. of Aerospace Engr., currently member of technical staff, EXXON Corp., member AIAA

${ }^{2}$ Professor, Dept. of Aerospace Engr., AIAA Fellow
} 
and formaldehyde $\left(\mathrm{CH}_{2} \mathrm{O}\right)$ imaging. Previously the authors reported an analysis that explains the flame blowout limits [1] that included a correlation based on a fairly complex set of parameters that are suggested by the analysis. In the present work a correlation of the blowout limits was determined purely in an empirical way; this leads to simpler relations but they are not tied to the theoretical concepts discussed in Ref. 1.

It is known that the most important non-dimensional scaling parameter in the theory of flame stability is the Damkohler number ${ }^{1-5}$. This number often is used to scale the combustor, i.e., to relate the required step height $(\mathrm{H})$ measured in a laboratory scale device to that required for a full-scale engine. The Damkohler number is defined as:

$$
D a=\frac{\text { flow time }}{\text { reaction time }}=\frac{\left(H / U_{o o}\right) \cdot f_{1}}{\left(\alpha_{0} / S_{L}^{2}\right) \cdot f_{2}}
$$

The flow time that appears in the numerator of Eq. 1 equals the characteristic length scale (the height $(\mathrm{H})$ of the cavity) divided by the air flow velocity $\left(\mathrm{U}_{\mathrm{oo}}\right)$, multiplied by the unknown function $\mathrm{f}_{1}$, which is a nondimensional function of the geometry of the cavity and other flow properties. The denominator contains the characteristic reaction time, where $\alpha_{0}$ is the thermal diffusivity at the combustor inlet conditions. $\mathrm{S}_{\mathrm{L}}$ is the stoichiometric laminar burning velocity, and $\mathrm{f}_{2}$ is an unknown nondimensional function of the actual chemistry, the mixing processes, the gas pressure, inlet temperature, and other parameters such as wall temperature. If the reactants are premixed, a common practice is to define the Damkohler number at flame blowout to be:

$$
D a_{\text {blowout }}=f_{3}(\phi)
$$

The function $\mathrm{f}_{3}$ is an unknown nondimensional function of the fuel-air equivalence ratio $\phi$. The functions $\mathrm{f}_{1}, \mathrm{f}_{2}$ and $\mathrm{f}_{3}$ can be determined by purely empirical methods by fitting curves to data, or they can be estimated from theoretical analysis.

Driscoll and Rasmussen [1] recently reported a theoretical analysis that provided the complicated form of the three functions $\left(f_{1}, f_{2}\right.$ and $\left.f_{3}\right)$ for the case of a nonpremixed flame stabilized in a wall cavity adjacent to a supersonic heated air flow. Fuel was injected directly into the cavity, and air was entrained into the cavity for this particular arrangement. Their analysis identified an overall equivalence ratio $\left(\phi_{0}\right)$. For the case of premixed systems, there have been many previous studies that report values of the function $\left(f_{1}, f_{2}\right.$ and $\left.f_{3}\right)$, such as those of Ozawa [6], Zukowski and Marble [7] and others [8-21]. For example, Fig.1 is the result of Ozawa for premixed kerosene-air conditions in an afterburner. It is seen that the stable region is surrounded by a rich limit and by a lean limit.

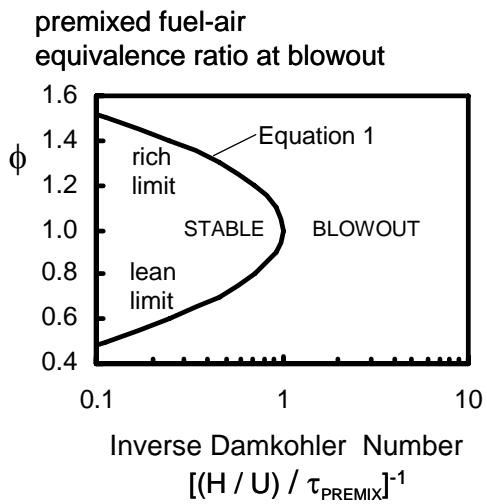

Figure 1. Plot of the Ozawa Curve [6] Which Correlates Blowout Limits of Premixed Subsonic Flames.

Ozawa defined the premixed time scale ( $\tau_{\text {PREMIX }}$ ) in Fig. 1 to be a function of pressure and inlet temperature of the premixed reactancts. For the case of nonpremixed reactants, there had been no single curve reported that is similar to that of the premixed curve of Ozawa until the recent correlation and the analysis presented by Driscoll and Rasmussen [1]. They considered a cavity-stabilized nonpremixed flame; their analysis is based on the fundamental theory that was developed by Vanquickenborne and van Tiggelen [22] for a lifted jet flame. Vanquickenborne and 
van Tiggelen proposed that the leading edge of the lifted flame is a premixed, turbulent flame and that the equilibrium requirement is:

$$
U=S_{b} \quad \text { at } \quad x=h
$$

where $U$ is the average gas velocity at the flame base, $S_{b}$ is the burning velocity, and $h$ is the liftoff height. Kalghatgi [23] extended this idea by assuming that the intensity of the turbulence controls the propagation speed, $S_{b}$, of the flame base and hence the liftoff height, $h$. Data of Upatnieks et al. [24] and Muniz and Mungal [25] appear to dispute the Kalghatgi explanation and indicate that the turbulence level does not control the liftoff height, but that edge-flame ideas are more appropriate.

For the premixed case that is associated with high-speed flow in afterburners, Zukoski and Marble [7] outlined a theory of flame stabilization behind a bluff body. They proposed that the limiting times scale is the residence time of fluid elements in the shear layer. This is where fresh reactants come into contact with the hot recirculation zone. For the case of nonpremixed reactants, Kalt et al. [26] considered a fuel jet surrounded by a bluff body and coaxial air flow; they found that as the jet velocity decreases toward lean blowout, the co-flow dominates the flowfield and the flame is confined to the recirculation zone. For high speed flows, a wall cavity causes lower pressure losses than traditional bluff-bodies or struts and the cavity wall is easier to cool than struts. Cavities were used in a supersonic combustor simulating flight Mach numbers of 4.5 that was reported by Mathur et al. [27]. Direct fueling of the cavity provides a more desirable fuel distribution within the cavity than injecting the fuel upstream of the cavity and allowing in to be entrained into the cavity, as was demonstrated by Gruber et al. [13]. Averaged $\mathrm{OH}$ fluorescence images of Gruber et al. [13] indicate that the flame location changes as the fuel flow rate and injector locations are varied.

Figure 2 provides a physical explanation of the flame blowout limit. First consider the rich limit which is defined as the condition for which an excessive mass flow rate of fuel is injected, causing the flame to blowout. The solid line within the shear layer in Fig. 2 represents the stoichiometric contour. Experiments have confirmed that a
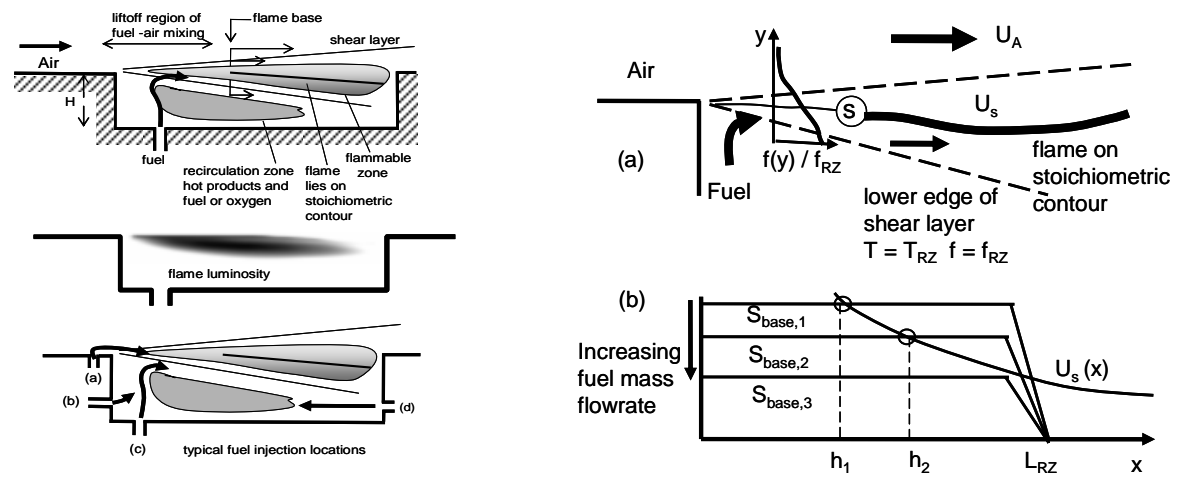

Figure 2. Left side: Components of the Shear Layer in the Nonpremixed Cavity Flames Considered and a Photograph of the Flame Emission From Mach 2.0 Supersonic Cavity-Stabilized Flame of Ref. 1, Showing that the Flame is Stabilized in the Shear Layer. A flammable zone exists between the air stream and the recirculation zone. Right side: A Physical Explanation of the Rich Blowout Limit. (a) Heat transfer from hot products in the recirculation zone increases the temperature at lower edge of shear layer $\left(T_{R Z}\right)$. (b) Increasing the fuel flow rate mixes cold fuel into the recirculation zone, reduces $T_{R Z}$ and the flame propagation speed $S_{\text {base }}$ until it is less than the oncoming gas velocity, so the liftoff height (h) moves downstream.

lifted nonpremixed jet flame is located along the stoichiometric contour. The curve labeled " $\mathrm{U}_{\mathrm{s}}(\mathrm{x})$ " in Fig. 2 represents the gas velocity along that contour. Even though the fuel and air are initially nonpremixed, there will be 
local premixing in the liftoff region, which is represented by the thin line to the left of the location "s" marked in Fig. 2. Studies of lifted subsonic jet flames have shown that the lifted flame base has a premixed flame character and it propagates into the locally premixed mixture, even though most of the fuel is consumed in the downstream nonpremixed flame region.

The horizontal lines labeled $S_{\text {base }}$ represent the propagation speed of the flame base. This propagation speed depends on the unburned gas temperature just upstream of the flame base, which is elevated because of heat transfer from the hot gases in the recirculation zone. The $x$-location where the curve of gas velocity $\mathrm{U}_{\mathrm{s}}$ crosses over the curve of propagation speed $S_{\text {base }}$ in Fig. 2 is the liftoff height $h_{1}$. As the fuel flow rate is increased toward the rich limit, more cold fuel enters the recirculation zone, so the fuel and products in the recirculation zone become cooler, so the gas temperature upstream of the flame base decreases. This causes the curves of propagation speed $\left(\mathrm{S}_{\text {base }}\right)$ to decrease as shown. The liftoff distance (h) shown in Fig. 2 increases until it exceeds $\mathrm{L}_{\mathrm{Rz}}$ and the reactants are no longer preheated, so rich blowout occurs. In addition, the stoichiometric contour is forced to move upwards into the higher velocity free stream, which is destabilizing. Similar arguments are used to explain the lean limits [1].

The goals of the present study have been to:

a) Provide qualitative data on the lean blowout limits of a cavity flame in a supersonic air flow with well defined boundary conditions for a wide range of operating conditions;

b) Obtain images of the structure and location of the reaction zones using $\mathrm{CH}, \mathrm{OH}$ and formaldehyde PLIF measurements, which had not been available previously;

c) Develop a correlation of lean blowout limits of flames that are stabilized in directly-fueled wall cavities in supersonic flows.

\section{Experimental Approach}

Two experimental systems were used: The University of Michigan Supersonic Combustion Facility and Test Cell 19 at the Air Force Research Laboratory's Propulsion Directorate, at Wright-Patterson Air Force Base. The Michigan facility is a blow down Mach 2.2 supersonic wind tunnel shown in Fig. 3 that was used byYoon et al. [5], Huh et al. [18], and Bryant and Driscoll [28]. Run times are 20 minutes for flow rates of $0.4 \mathrm{~kg} / \mathrm{s}$. A $250 \mathrm{~kW}, 5$ $\mathrm{m}$ long electric heater heats the air to $650 \mathrm{~K}$.
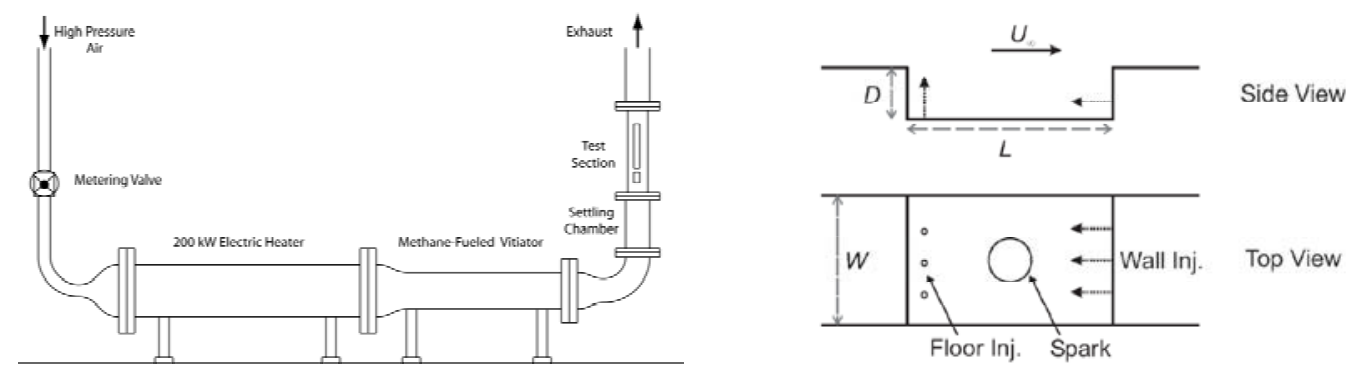

Figure 3: University of Michigan Supersonic Combustion Facility.

The nozzle was designed using the method of characteristics using the NOZCS2 code. Cavity LD4 has a depth, $D$, of $15.24 \mathrm{~mm}$ and a length, $L$, of $60.96 \mathrm{~mm}(L / D=4)$. The width, $W$, of the test section was $38.10 \mathrm{~mm}$. Fig. 4 is a photo of the cavity. Typical experimental conditions were: a stagnation pressure of $512 \mathrm{kPa}(5.1 \mathrm{~atm})$, a stagnation temperature of 530-620 K, static pressure of $36 \mathrm{kPa}$, static temperature of $258 \mathrm{~K}$, free stream velocity of $769 \mathrm{~m} / \mathrm{s}$. The PLIF system shown in Fig. 5 was used to image $\mathrm{CH}, \mathrm{OH}$ and formaldehyde $\left(\mathrm{CH}_{2} \mathrm{O}\right)$ in the cavity-stabilized flame. The YAG pumped dye laser was operated at $390.30 \mathrm{~nm}$. Fluorescence was detected from the A-X(1,1), A$\mathrm{X}(0,0)$ and $\mathrm{B}-\mathrm{X}(0,1)$ bands in the $420 \mathrm{~nm}-440 \mathrm{~nm}$ range. Formaldehyde PLIF was excited by the $355 \mathrm{~nm}$ output ( $50 \mathrm{~mJ} /$ pulse) of a Nd:YAG laser. It was possible to take advantage of the long fluorescence lifetime of CH2O by delaying the camera gate by 200 ns with respect to the laser pulse, so no filters were required to block Rayleigh scattering from the laser beam. Signal to background ratios were 10. Some of the blowout measurements were made in Test Cell 19 at AFRL described by Gruber et al. [13]. 

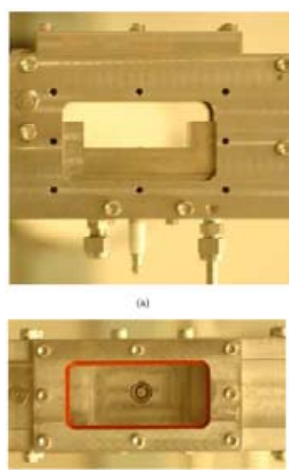

Figure 4: Photographs showing the (a) side view and (b) top view of the cavity.

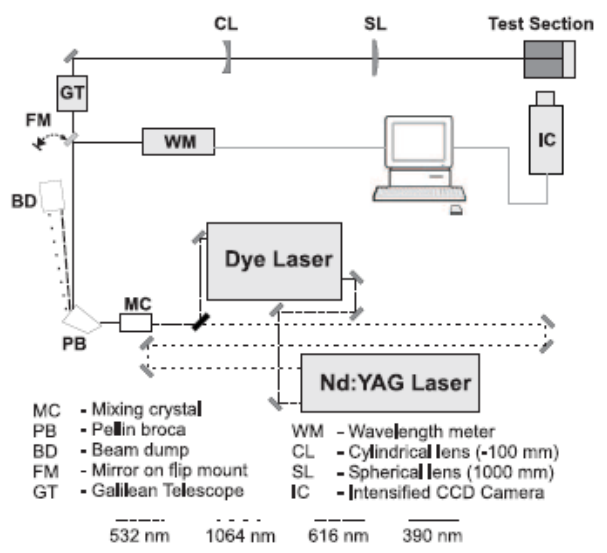

Figure 5. Schematic of the CH PLIF system.
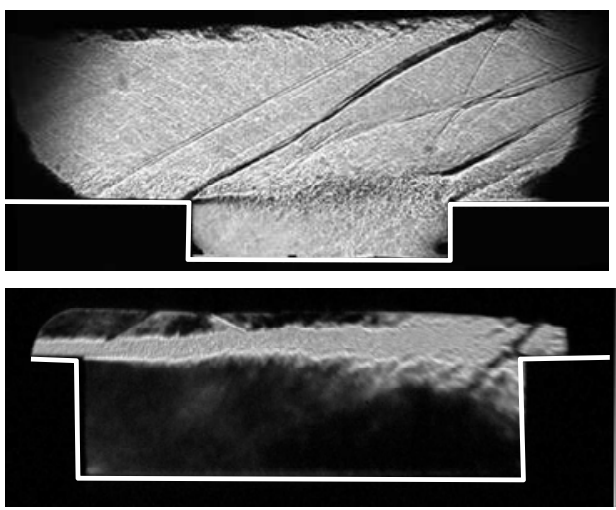

Figure 6: Schlieren photographs of the shear layer over the cavity in the nonreacting case. A shock wave is created near the upstream corner of the cavity by the shear layer, which acts as an obstacle. Expansion waves are seen near the downstream corner. Mach number of the airflow is 2.2. 


\section{Results: Images of Flame Location}

Figures 7a-c indicate the flame location for aft wall fueling, while Figs. 7d-f correspond to floor fuel injection. The chemiluminescence is displayed, along with schematics that summarize the PLIF observations. The approximate boundaries between the fuel-rich zones and hot recirculation zones were inferred from images of the $\mathrm{CH}, \mathrm{OH}$ and formaldehyde $\left(\mathrm{CH}_{2} \mathrm{O}\right)$ fluorescence that were reported in previous studies [2-4]. Formaldehyde indicates the fuel-rich zone, $\mathrm{OH}$ marks the hot recirculation zone products, and $\mathrm{CH}$ identifies the thin primary reaction layers. A first observation is that the flame location can be explained by the simple idea that a fuel jet is injected into a recirculation zone. The fuel initially is not mixed and is contained in the jet-like structure, but soon the fuel is convected by the recirculation flow pattern and moves toward the front of the cavity along the floor or along the front wall. During this time, heat is transferred from the hot combustion products to the rich mixture and some combustion may take place. When the fuel reaches the leading edge of the shear layer, where air is plentiful, fuel decomposition and combustion always occurs. This concept is much different from previous ideas that assumed that fuel and air mix immediately and that there is one equivalence ratio that characterizes all of the mixed fluid in the cavity.

The fuel flow rate for Fig. 7a is denoted a moderate fueling, which means that it is approximately halfway between the rich and lean blowout limits. For this moderate fueling case, the flame is "nearly attached" in that the fuel issues from the aft wall port and some flame is observed a few millimeters from the port, but little $\mathrm{CH}$ is recorded at the port, so the flame is not quite an attached jet flame. There must be enough air entrained into the cavity to support combustion on the upper side of the fuel jet, but not on the lower side, since chemiluminescence is observed at the top of the jet but is not observed in the lower and front regions of the cavity, which are too fuel-rich to support combustion. The fuel jet enters the recirculation zone, which is rotating in a clockwise direction, so the fuel eventually is directed upwards toward the upstream portion of the shear layer. Fig. 7a shows that flame exists along the entire shear layer. The fuel enters the shear layer from below and air enters from above. The shear layer flame is stabilized at the beginning of the shear layer, so it is concluded that the gas velocity at the beginning of the shear layer (just behind the upper front corner of the cavity) is sufficiently low such that the flame speed equals the local gas velocity.

In Fig. $7 \mathrm{~b}$ the lean limit conditions are displayed ( $0.8 \mathrm{~g} / \mathrm{s}$ of ethylene). There is still some flame on the upper side of the fuel jet (in the middle of the cavity), but the shear layer flame is no longer stabilized at the beginning of the shear layer. There is no flame in the front portion of the cavity. The shear layer flame begins at a location about halfway between the upstream and downstream corners of the cavity. Near the lean limit, the amount of fuel in the cavity is less than the ideal (moderate fueling) case. Some theories assume that the fuel and air are fully mixed - and the lean mixture is no longer flammable. However our PLIF imaging work [2, 3] shown that this is not so. If the fuel and air were fully mixed, the luminosity in Fig. 7 would be uniformly distributed throughout the cavity, and it is not. Even at the lean limit there is a jet of pure fuel that has become relatively short, and there are stoichiometric layers that surround the fuel jet. The reduced amount of fuel is believed to cause a significant decrease in the temperature of the mixture of products and air in the recirculation zone. Blowout occurs when the local flame speed of the heated fuel-air mixture (in layers near the fuel-air boundary) decreases to less than the local incoming gas velocity. Sufficient heat must diffuse from the recirculation zone to the fuel-air mixture (near the fuelair boundary) to increase the flame speed above that of a cold mixture, so a hot recirculation zone is required to stabilize flames in high-speed flows. The reason why there is no reaction in the front of the cavity is believed to be because the short fuel jet from the aft wall has added heat to the fluid in the rear portion of the cavity, but the fluid in the front of the cavity is too far away and becomes too cold to support a flame.

The rich limit observed in Fig. 7c has the same general flame structure as the lean limit. That is, there is no flame in the front of the cavity at the rich limit. It is believed that the front of the cavity has no flame because conditions are too fuel-rich in this case. The cavity is flooded with too much fuel, except near the downstream corner where air is forced into the cavity where the shear layer impinges on the aft wall. The front half of the shear layer also has no flame, even though there is air available directly above the shear layer. This is believed to be due to the reduced temperatures of the recirculation zone product gases at the rich limit. Proper flame stability requires an optimization of the size and locations of the flammable regions (which occur near the fuel jet-entrained air boundaries) and the location and temperature of the recirculation zone. 
For the case of fuel injection from the floor location, Figs.7d-f show that there is more flame in the front of the cavity than for Figs. 7a-c. This is not unexpected, since the floor injector is near the front of the cavity at the location indicated by the arrow. In all cases seen in Figs 7d-f, the flame is stabilized at the upstream boundary of the shear layer or just below it. The fuel jet issues directly upward toward the shear layer, and there is less air in the

\section{aft wall fuel injection:}

a

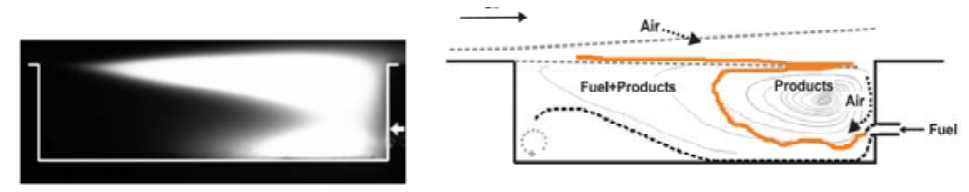

moderate fuel flow rate - shear layer flame

b

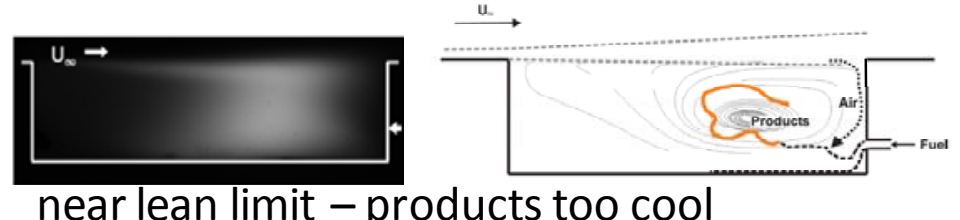

C

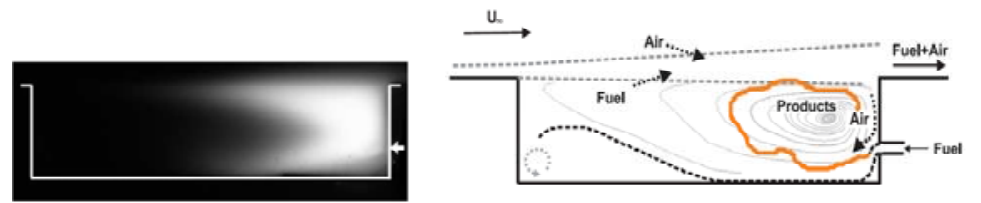

near rich limit - front of cavity flooded

floor fuel injection:
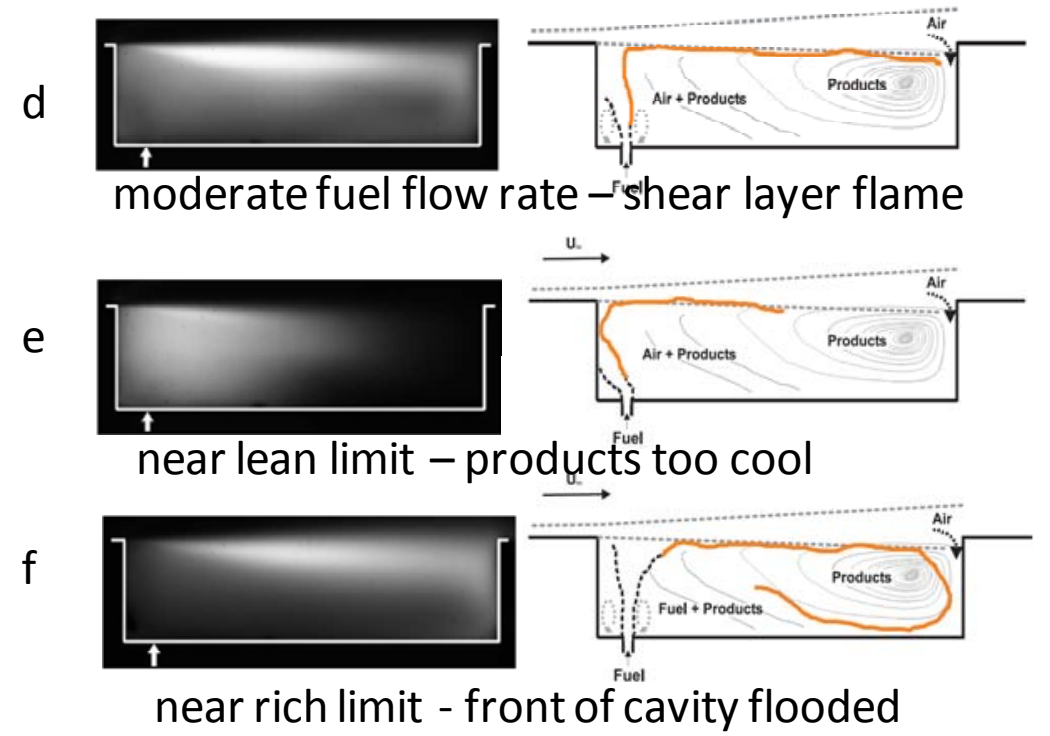

Figure 7: Time-averaged chemiluminescence from cavity stabilized flames. Left side: fuel injected into cavity from aft wall at location marked by arrow. Right side: fuel injected from floor at location marked by arrow. Mach 2.2 air flow is heated to $430 \mathrm{~K}$. Ethylene fuel. (a) moderate fuel flow rate, (b) lean limit, (c) rich limit.

front portion of the cavity because most of the air is entrained at the rear corner and must mix with products and fuel as it recirculates. At the rich limit (Fig. 7f) there is a lack of observed OH lower upstream corner of the cavity [2, 3] and this leads to the conclusion that it is flooded and contains a high concentration of unburned fuel. Near the rich 
limit, fuel injection from the floor of the cavity offers significant advantages over aft wall injection. However the opposite is true near the lean limit. With floor injection the fuel issues directly toward the shear layer, as shown on the right side of Fig. 11. The fuel quickly accelerates in the shear layer so a percentage of the fuel can escape without reacting. The cavity is not likely to be flooded with fuel with floor injection, which is helpful near the rich limit. Quenching of the flame due to the accumulation of cold fuel is less likely to happen with floor injection. However, near the lean limit it is desirable to fill as much of the cavity with fuel as is available, so floor injection is not preferred, since the fuel is quickly directed to the shear layer and leaves the cavity.

\section{Results: Correlation of Measured Flame Blowout Limits}

The overall equivalence ratio $\left(\phi_{0}\right)$ is defined as the mass flow rate of fuel divided by the characteristic mass flow rate of air $\mathrm{m}_{\mathrm{A}}^{*}$, divided by $\mathrm{r}_{\mathrm{s}}$, the stoichiometric fuel-air ratio. To define the characteristic mass flow rate of air into the cavity, only a portion of the free stream air should be considered. Winterfeld [11] and Driscoll and Rasmussen [1] argue that a characteristic amount of air entrained into the shear layer above the cavity is:

$$
\mathrm{m}^{*}{ }_{\mathrm{A}}=0.01 \rho_{\mathrm{A}} \mathrm{U}_{\mathrm{A}} \mathrm{HW}
$$

It is not necessary that the exact amount of air that enters the cavity be known. The entrained mass flow of air is proportional to the value given by Eq. $4[1,11]$ but $\mathrm{m}_{\mathrm{A}}$ is a characteristic scaling quantity used to correlate the data, and is not the exact amount of entrained air. It also is noted that the overall equivalence ratio $\left(\phi_{0}\right)$ also is a characteristic scaling quantity that is not the actual equivalence ratio of fluid in the cavity.

Some blowout data is displayed in Fig. 8 (left side) for lean conditions in the AFRL facility. Comparison of lines A and F indicates that the location of the fuel injector has a significant effect on the lean blowout limits. Curve A represents the best case since it is the least amount of fuel required for stability. It corresponds to wall injection of ethylene fuel into the ramped cavity (22:5 \pm aft wall angle). Curve $\mathrm{F}$ is much higher than $\mathrm{A}$ and represents blowout limits from the same conditions as A except that fuel was injected using the floor injection
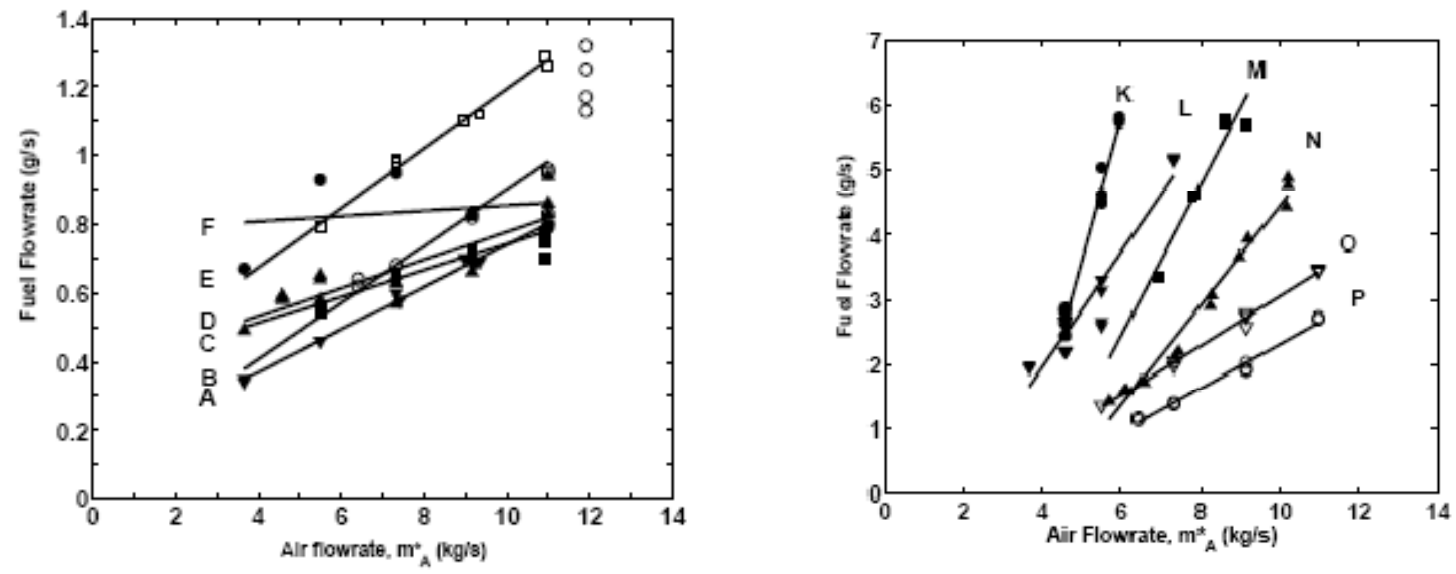

Figure 8: Left side: Lean blowout limits; Right side: Rich blowout limits. Curve (A) = ethylene, wall injection, ramped cavity; (B)= methane, wall injection, ramped cavity; (C) = ethylene, floor injection, rectangular cavity; (D) = ethylene, wall injection, rectangular cavity; $(\mathrm{E})$ = methane, wall injection, rectangular cavity; $(\mathrm{F})=$ ethylene, floor injection, ramped cavity. $(\mathrm{K})$ = ethylene, wall injection, ramped cavity; $(\mathrm{L})=$ ethylene, wall injection, rectangular cavity; $(\mathrm{M})$ = ethylene, floor injection, ramped cavity; $(\mathrm{N})$ = ethylene, wall injection, ramped cavity; $(\mathrm{O})$ = methane, wall injection, rectangular cavity; and $(\mathrm{P})=$ methane, wall injection, ramped cavity.

scheme. Rich blowout limits from tests at AFRL are plotted in Fig. 8 (right side) where stable flames correspond to conditions below the curves. It was found that the floor injectors performed better than the wall injectors in all cases at the rich limit, which is the opposite of the lean blowout trends. For example, curve $\mathrm{M}$ (floor injection) lies above curve $\mathrm{N}$ (wall injection) and the higher curve represents improved stability at the rich limit. 
Inspection of Fig. 8 indicates that wider flame stability limits always corresponded to fuels that have larger values of laminar burning velocity. Ethylene flames always were more stable than methane flames as illustrated by curves D and E in Fig. 8. Curve D (ethylene) lies below curve E (methane) for the same conditions (Mach 2, wall injection, rectangular cavity). Hydrogen fuel led to the most stable operation, followed by acetylene, ethylene and methane.

The Damkohler number used to correlate the blowout data in the present paper is defined to be:

$$
D a=\frac{H / U_{O O}}{\left(\frac{a_{0}}{S_{L 0}^{2}}\right)\left(\frac{1 a t m}{p}\right)\left(\frac{300 K}{T}\right)}
$$

$S_{L, 0}$ is the stoichiometric laminar burning velocity and $\alpha_{0}$ is the thermal diffusivity; both are evaluated at $300 \mathrm{~K}, 1$ atm.. Fig. 9a shows a correlation of the lean blowout data for cavities with aft wall injection of fuel. For aft wall fuel injection, the best fit to data in Fig. 9a is:

$$
\phi_{0}=0.0043 \mathrm{Da}^{-0.26}
$$
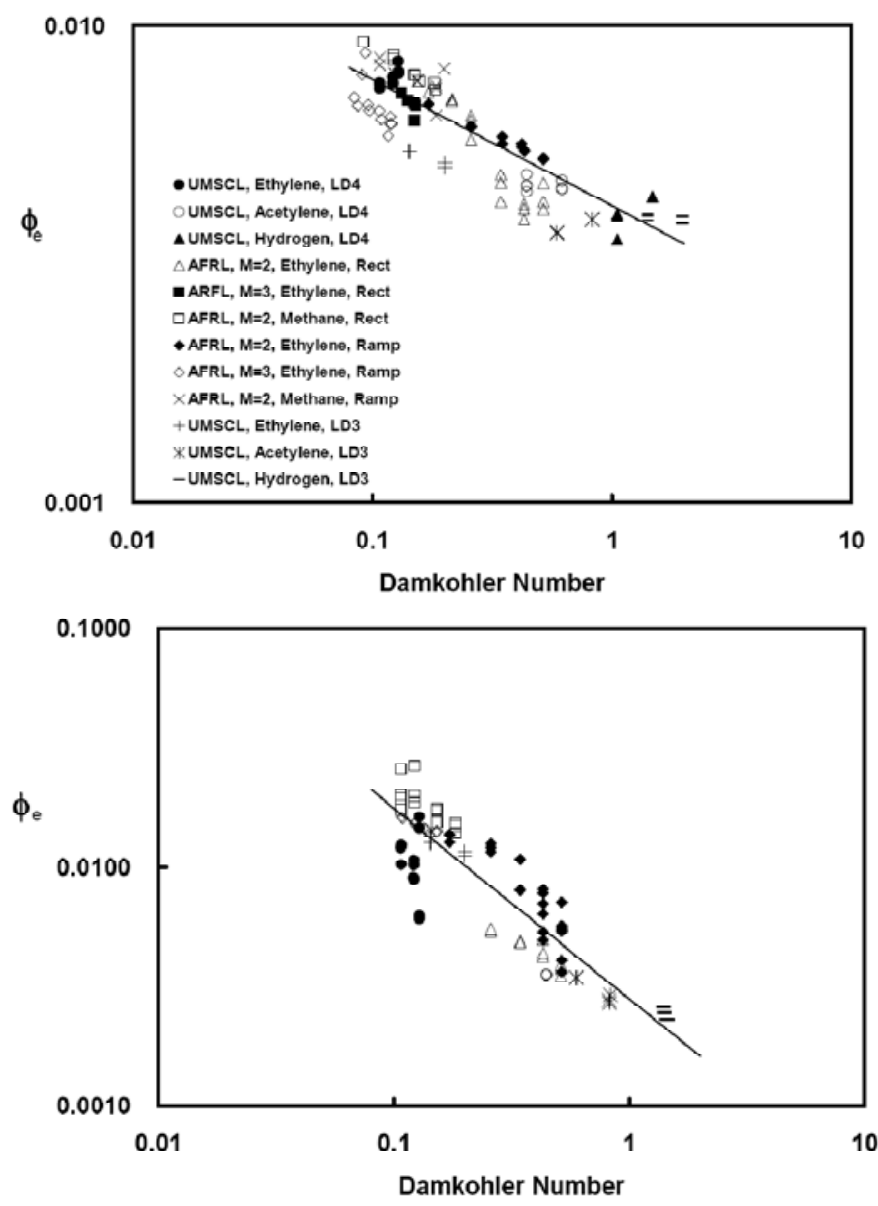

Figure 9: Correlation of lean blowout limits of the present study. Flames are stabilized in a wall cavity that is directly fueled. Plot (a): fuel injected through aft wall injectors and (b) fuel injected through floor injectors. Three fuels (ethylene, acetylene, methane), two Mach numbers (2.4 and 3), and 22:5 \pm ramped and 90 \pm rectangular aft walls.

Da is defined by Eq. 5 and overall fuel-air equivalence ratio $\left(\phi_{0}\right)$ is defined using the characteristic mass flow rate given by Eq. 4. Eq. 6 indicates that increasing the Damkohler number (for example, by increasing the cavity height 
$\mathrm{H}$ or increasing the burning velocity $\mathrm{S}_{\mathrm{L} 0}$ ) will cause the flame to be stabilized for leaner (smaller $\phi$ ) conditions. Increasing the static pressure or the air stream temperature $\mathrm{T}$ also leads to improved lean flame stability. For the case of floor injection of the fuel into the cavity, the correlation of the lean limit blowout data is shown in Fig. 9b. The best fit to the data is:

$$
\phi_{0}=0.0028 \mathrm{Da}^{-0.80}
$$

Da defined by Eq. 5. The two equations (Eq. 6 and 7) are different, indicating that the location of fuel injection (aft wall or floor injection) causes a significant difference in the nondimensional lean blowout limits.

\section{Results: Discussion of Cavity Flameholder Design}

The images and the blowout data suggest that there are three guidelines to follow to effectively design cavity fuel injection systems. First, fuel injection should occur in close proximity to the primary recirculation zone. The floor injectors were located near the front wall of the cavity, so the hot products and air required for ignition near the injector must be convected along the entire length of the cavity. In contrast, the distance between the wall injectors and the heat release zone was on the order of the cavity height. This may account for the lower lean blowout limits that were achieved when using the wall injection scheme. Both of the injection systems that were considered injected the fuel in a direction that was in concert with the bulk flow direction, so nothing conclusive can be said about the optimal direction for fuel injection. The second guideline suggests that it is desirable to allow excess fuel to escape from the cavity. Fuel buildup occurred in the front of the cavity with wall injection because the fuel was directed into the relatively stagnant, upstream half of the cavity. Fuel could easily escape when floor injectors were used, since fuel was directed toward the shear layer where it could escape to the free stream. Consequently, when the floor injectors were used, a flame could be sustained to much higher flow rates than when wall injectors were used. Of course, fuel escaping to the free stream will reduce combustion efficiency .

A third guideline is that operating conditions should not alter the flow in a way that disrupts the recirculation zone. This is a very challenging criterion, since the flow field with reaction present is not often known apriori. However, in the case of a dual-mode scramjet, boundary layer separation upstream of the cavity is expected. Therefore, the fuel from the floor injectors will no longer be contained by the shear layer spanning the cavity. As a result, the hot products are directed into the free stream where they may not be recirculated to the flame base for assisting with stabilization. When wall injectors are used, the fuel is forced to enter the cavity and a flame can be maintained even when the boundary layer has separated. This was demonstrated by Gruber et al. [28] and has made the floor injection scheme less desirable than aft wall injection. The results of the present work have identified some positive and some negative attribute of both floor and aft wall injection schemes.

\section{Conclusions}

Blowout limits were measured for flames stabilized within a cavity that is adjacent to a heated supersonic air stream. Fuel was injected directly into the cavity from two locations: the floor and the aft wall. The flames were visualized using chemiluminescence imaging, $\mathrm{OH}, \mathrm{CH}$ and formaldehyde $\left(\mathrm{CH}_{2} \mathrm{O}\right)$ PLIF. CH PLIF identified the relatively thin primary reaction layers, while OH PLIF identified regions of hot combustion products. $\mathrm{CH}_{2} \mathrm{O}$ PLIF identified the region of initial fuel breakdown. The following conclusions were reached.

1. Chemiluminescence and PLIF images show that the flame structure and location is dependent upon the fuel injection scheme. When fuel is injected from the aft wall, a first flame propagates against the fuel jet and a second flame exists in the shear layer. In contrast, when a floor fuel injector is used, a single flame extends from the injector and into the shear layer.

2. The flame structure is highly dependent upon the fuel flowrate. Robust flames are observed in the shear layer for both fuel injection schemes at moderate fuel flowrates, which are halfway between the lean and rich blowout points. At lean fu- eling rates, the length of the shear layer flame decreases and more combustion takes place in the cavity volume. Near the rich blowout point, the cavity becomes flooded with fuel when wall injectors are used. With fuel 
injection from the floor, unburned fuel escapes through the shear layer and rich blowout is much less likely to occur than with wall injection.

3. Flames were attached or slightly lifted from the injector for all cases. Thin, continuous $\mathrm{CH}$ layers extending from the injector were similar in character to lifted jet flames. Low formaldehyde concentration in this region indicates the mostly non-premixed nature of the injector flames.

4. Thick $\mathrm{CH}$ zones were sometimes observed in the shear layer in contrast to the thin layers detected in the cavity. Broad CH structures have never been observed in CH PLIF studies and suggest that high turbulence levels alter the character of the reaction zones.

5 Both lean and rich blowout limits were highly dependent upon fuel injector location, which indicates that modeling a directly-fueled cavity as a well-stirred reactor is not appropriate. Well-stirred reactor concepts assume that mixing is so rapid that only the values of mass flow rates of fuel and air are important, and the locations where they are injected are assumed to be not important. Wall fuel injectors provided better flame stability near the lean limit, while floor injectors were better near the rich limit.

6. Variations in cavity geometry had a measurable effect on the blowout limits. Lean blowout occurred at lower fuel flow rates in the cavity with a length-to-depth ratio of 3 than in the cavity with a length-to-depth ratio of 4 . No measureable differences in the blowout limits were noted as the angle of the cavity aft wall was varied.

7. Successful correlation of lean blowout limits in the directly-fueled wall cavity was achieved using a global Damkohler number. By inspecting the data, a chemical time scale was determined that adequately incorporate the effects of fuel-type into the correlation. That is, using the selected chemical time scale, lean blowout limits for hydrogen, ethylene, acetylene and methane fuels collapsed to a single curve.

\section{Acknowledgments}

Support for the Michigan experiments was provided by the NASA funded URETI Reusable Launch Vehicle Center; experiments conducted at AFRL were supported the Air Force Office of Scientific Research, monitored by Dr. Julian Tishkoff.

\section{References}

1. Driscoll, J.F. and Rasmussen, C. C., "Correlation and Analysis of Blowout Limits of Flames in High-Speed Airflows”, J. Propulsion and Power, Vol. 21, No. 6, p. 1035, 2005.

2. Rasmussen, C.C., Dhanuka, S., and Driscoll, J.F., "Visualization of Flameholding Mechanisms in a Supersonic Combustor Using PLIF, Proc. Combust. Inst. 31, 2505-2512, 2007.

3. Rasmussen, C.C., Driscoll, J.F., Carter, C.D., Hsu, K.-Y., "Characteristics of Cavity-Stabilized Flames in a Supersonic Flow”, J. Propulsion Power 21, 4, 765, 2005.

4. Rasmussen, C. C., Driscoll, J.F., Hsu, K.Y., Donbar, J.M., Gruber, M., Carter, C.D., "Stability Limits of CavityStabilized Flames in Supersonic Flows”, Proc. Combustion Institute 30, 2004, 2825-2931.

5. Yoon, Y., Donbar, J.M., and Driscoll, J.F., "Blowout Stability Limits of a Hydrogen Jet Flame in a Supersonic, Heated Coflowing Air Stream”, Combustion Science and Technology Vol. 97, No. 1, 1994, pp. 137-156.

6. Ozawa, R.I., "Survey of Basic Data on Flame Stabilization and Propagation for High Speed Combustion Systems”, U.S. Air Force AFAPL Technical Report TR-70-81, 1970.

7. Zukoski, E.E., and Marble, F.E., "Experiments Concerning the Mechanism of Flame Blowoff from BluffBodies”, Proceedings of the Gas Dynamics Symposium on Thermochemistry, Northwestern U., Evanston, IL, 1956, pp. 205-225.

8. Plee, S.L. and Mellor, A.M., "Characteristic Time Correlation for Lean Blowoff of Bluff-Body Stabilized Flames”, Combustion and Flame Vol. 35, No.1, 1979, pp. 61-80.

9. Kundu, K., Banerjee, D., and Bhaduri, D., "Theoretical Analysis on Flame Stabilization by a Bluff-Body", Combustion Science and Technology Vol. 17, Vol. 1, 1977, pp. 153-162.

10. Baxter, M.R. and Lefebvre, A.H., "Flame Stabilization in High-Velocity Heterogeneous Fuel-Air Mixtures", Journal of Propulsion and Power Vol. 8, No. 6, 1992, pp. 1138-1143. 
11. Winterfeld, G. “On the Process of Turbulent Exchange Behind Flame Holders”, Proceedings of the Combustion Institute Vol. 10, 1965, pp. 1265-1275.

12. Winterfeld, G. "Investigations on the Stabilization of Hydrogen Diffusion Flames in Supersonic Flow", DFVLR (Deutschen Forshungs-und Versuchsanstalt fur Luft und Raumfahrt) Report FB-76-35, 1976.

13. Gruber, M. R., Baurle, R.A., Mathur, T. and Hsu, K.-Y., "Fundamental Studies of Cavity-Based Flameholder Concepts for Supersonic Combustors”, Journal of Propulsion and Power Vol. 17, No. 1,2001, pp. 146-153.

14. Gruber, M.R., Donbar, J.M., Carter, C.D., and Hsu, K.-Y., "Mixing and Combustion Studies Using CavityBased Flameholders in a Supersonic Flow", Journal of Propulsion and Power, Vol. 20, No. 5, 2004, pp. 769778.

15. Ben-Yakar, A. and Hanson, R.K., "Cavity Flame-Holders for Ignition and Flame Stabilization in Scramjets: an Overview”, Journal of Propulsion and Power Vol. 17, No. 4, 2001, pp. 869-877.

16. Niioka, T., Terada, K., Kobayashi, H., Hasegawa, S., "Flame Stabilization Characteristics of a Strut Divided into Two Parts in Supersonic Airflow", Journal of Propulsion and Power Vol. 11, No. 1, 1995, pp. 112-115.

17. Northam, G.B., Trexler, C.A., and McClinton, C., "Flame-holding Characteristics of a Swept Strut Hydrogen Fuel Injector for Scramjet Application”, NASA TR A81-10711, 1981.

18. Huh, H., and Driscoll, J.F., "Shock-Wave Enhancement of the Mixing and Stability Limits of Supersonic Hydrogen-Air Jet Flames”, Proceedings of the Combustion Institute Vol. 26, 1996, pp. 2933-2939.

19. Schefer, R.W., Namazian, M., Kelly, J., and Perrin, M., "Effect of Confinement on Bluff-Body Burner Recirculation Zone Characteristics and Flame Stability”, Combustion Science and Technology Vol. 120, No. 1, 1996, pp. 185-211.

20. Owens, M.G., Tehranian, S., Segal, C., ”Flame-holding Configurations for Kerosene Combustion in a Mach 1.8 Airflow", Journal of Propulsion and Power Vol. 14, No. 4, 1998, pp. 456-461.

21. Bovina, T.A., "Studies of Exchange Between Re-Circulation Zone Behind the Flame-Holder and Outer Flow", Proceedings of the Combustion Institute Vol. 7, 1959, pp. 692-704.

22. Vanquickenborne, L, and van Tiggelen, A., "The Stabilization Mechanism of Lifted Diffusion Flames", Combustion and Flame Vol. 10, No. 1, 1966, pp. 59-72.

23. Kalghatgi, G. "Blow-Out Stability of Gaseous jet Diffusion Flames in Still Air", Combustion Science and Technology Vol. 26, No. 3, 1981, pp. 233-239.

24. Upatnieks, A., Driscoll, J.F.,Rasmussen, C.C., and Ceccio, S.L.,"'Liftoff of Turbulent Jet Flames - Assessment of Edge Flame and Other Concepts Using Cinema-PIV Diagnostics”, Combustion and Flame Vol. 138, No. 3, 2004, pp. 259-272.

25. Muniz, L., and Mungal, M.G., "Instantaneous Flame-Stabilization Velocities in Lifted Jet Diffusion Flames", Combustion and Flame Vol. 111, No. 1, 1997, pp. 16-31.

26. Kalt, P.A, Al-Abdeli, Y.M., Masri, A.R., and Barlow, R.S., "Swirling Turbulent Non-Premixed Flames of Methane: Flow Field and Compositional Structure”, Proceedings of the Combustion Institute, Vol. 29, 2002, pp. 1913-1919.

27. Mathur, T., Gruber, M., Jackson, K., Donbar, J., Donaldson, W., Jackson, T., Billig, F., 2001. Supersonic combustion experiments with a cavity-based fuel injector. Journal of Propulsion and Power 17 (6), 1305, 1312.

28. Gruber, M. R., Baurle, R. A., Mathur, T., Hsu, K.-Y., 2001. Fundamental studies of cavity-based flameholder concepts for supersonic combustors. Journal of Propulsion and Power 17 (1), 146, 153.

29. Bryant, R. and Driscoll, J. F. "The Structure of Supersonic Hydrogen-Air Flames", AIAA Journal 39: 9, 17351741, 2001. 